\title{
PET Imaging of Human Gliomas with Ligands for the Peripheral Benzodiazepine Binding Site
}

\author{
Larry Junck, MD, James M. M. Olson, BS, † Brian J. Ciliax, PhD,* Robert A. Koeppe, PhD, \\ G. Leonard Watkins, PhD, $\ddagger$ Douglas M. Jewett, PhD, $\ddagger$ Paul E. McKeever, MD, PhD,§ Donald M. Wieland, PhD, \\ Michael R. Kilbourn, $\mathrm{PhD}$, $\ddagger$ Simon Starosta-Rubinstein, MD, I William R. Mancini, $\mathrm{PhD}, \div$ \\ David E. Kuhl, MD, $\ddagger$ Harry S. Greenberg, MD,* and Anne B. Young, MD, PhD*
}

Human gliomas were imaged in vivo using ligands for the peripheral-type benzodiazepine binding site (or $\omega_{3}$ binding site) and positron emission tomography (PET). Although gliomas have a high density of the peripheral-type benzodiazepine binding site, PET scans with a selective ligand for this site, $\left[{ }^{11} \mathrm{C}\right]$ Ro5-4864, failed to demonstrate higher radioactivity levels in human gliomas than in brain. In vitro studies of surgically removed specimens of human glioma demonstrated little binding of Ro5-4864 but high levels of binding of another selective ligand, PK 11195. Scans with $\left[{ }^{11} \mathrm{C}\right]$ PK 11195 demonstrated increased radioactivity in glioma compared to brain in 8 of 10 patients. Radioactivity in turnor and the ratios of radioactivity in tumor to that in remote gray and in white matter correlated significantly with the specific activity of $\left[{ }^{11} \mathrm{C}\right] \mathrm{PK} 11195$, suggesting that accumulation represents saturable high-affinity binding. We conclude that the PK 11195 manifests greater binding than Ro5-4864 to the peripheral-type benzodiazepine binding site on human gliomas and that human gliomas can be successfully imaged using [ $\left.{ }^{11} \mathrm{C}\right] \mathrm{PK} 11195$ and PET.

Junck L, Olson JMM, Ciliax BJ, Koeppe RA, Watkins GL, Jewett DM, McKeever PE, Wieland DM, Kilbourn MR, Starosta-Rubinstein S, Mancini WR, Kuhl DE, Greenberg HS, Young AB. PET imaging of human gliomas with ligands for the peripheral benzodiazepine binding site. Ann Neurol 1989;26:752-758

A technique for imaging the extent and viability of a glioma without depending on abnormal permeability of the blood-brain barrier would be of great value in the diagnosis and management of tumor. At present the diagnosis and treatment of gliomas rely primarily on $\mathrm{x}$-ray computed tomography (CT) and magnetic resonance imaging (MRI). The contrast enhancement typically present in high-grade gliomas with CT or MRI and contrast agents delineares a region of increased permeability of the blood-brain barrier that correlates well with the solid tumor mass [1-6]. However, CT is often unsatisfactory for demonstrating tumor regions with normal permeability of the bloodbrain barrier, including most low-grade gliomas and the infiltrating portions of high-grade gliomas [1-4]. MRI reveals a more extensive abnormality than CT but cannot reliably distinguish tumor from peritumoral edema [4-7]. Neither technique can accurately differentiate gliomas from other tumors such as brain metastases, and neither can distinguish viable tumor from largely necrotic tumor $[7,8]$.
A promising approach to imaging gliomas employs radiolabeled ligands for the peripheral-type benzodiazepine binding site (PBBS), also known as the $\omega_{3}$ binding site [9]. The "peripheral" notation indicates that this site is normally present in highest density in certain tissues outside the central nervous system (CNS) including the adrenal gland, lung, kidney, heart, and skin [10]. Selective ligands for the PBBS include the benzodiazepine R05-4864 and the isoquinoline derivative PK 11195, while nonselective ligands including the benzodiazepine flunitrazepam bind to the PBBS but also to central benzodiazepine receptors. The PBBS is present in low density in the normal brain and is thought to be located primarily on glia rather than on neurons [11-14].

Several studies indicate that the PBBS is present on gliomas in high density. Specific binding to the PBBS is greatly increased in C6 rat gliomas and U87 human gliomas implanted in rat brains and studied in vitro and in vivo [10]. In vivo accumulation of PBBS ligands in gliomas in rats can be blocked with unlabeled ligand,
From the ${ }^{*}$ Department of Neurology, $\uparrow$ Department of Pharmacology, ¥Division of Nuclear Medicine (Department of Internal Medicine), and \$Department of Pathology, University of Michigan, Ann Arbor, MI; and TUniversidad Central de Venezuela, Caracas, Venezuela.
Received Jan 17, 1989, and in revised form May 9. Accepted for publication May 9, 1989.

Address correspondence to Dr Junck, Department of Neurology, 1914/0316 Taubman Center, University of Michigan, Ann Arbor, MI 48109. 
indicating that it depends on specific binding rather than disruption of the blood-brain bartier [15]. Binding of PBBS ligands is high in human gliomas studied in vitro $\{16,17\}$, and $\mathrm{PBBS}$ ligands can demonstrate infiltrating portions of tumors and differentiate viable tumor regions from largely necrotic regions [15-17].

We investigated the imaging of human gliomas in vivo using positron emission tomography (PET) with radiolabeled Ro5-4864 and PK 11195.

\section{Methods}

\section{Patients}

Five patients with gliomas were scanned with $\left[{ }^{11} \mathrm{C}\right] \mathrm{Ro} 5$ 4864. All had astrocytomas grade II (astrocytoma), III (anaplastic astrocytoma), or IV (glioblastoma) according to the diagnostic criteria of the World Health Organization [18], but two of the tumors also contained regions of oligodendroglioma. Three patients had been treated with radiotherapy, and one of these had received chemotherapy. Ten patients with astrocytomas were scanned with $\left[{ }^{11} \mathrm{C}\right] \mathrm{PK} 11195$. Nine had astrocytomas grade II, III, or IV, and one had an astrocytoma that could not be assigned a grade. Seven patients had been treated with radiotherapy, and 4 of these had also received chemotherapy. These studies were approved by the institutional review board, and informed consent was obtained from all patients.

\section{Positron Emission Tomography}

$\left[{ }^{11} \mathrm{C}\right]$ Ro5-4864 and $\left[{ }^{11} \mathrm{C}\right] \mathrm{PK} 11195$ were synthesized by $N$ alkylation of their desmethyl precursors using $\left[{ }^{11} \mathrm{C}\right]$ methyl iodide. Ro5-4864 is $4^{\prime}$-chlorodiazepam, or 7-chloro-5-(4chlorophenyl)-1,3-dihydro-1-methyl-2H-1,4-benzodiazepin2-one. PK 11195 is 1-(2-chlorophenyl)-N-methyl-N(1-methylpropyl)-3-isoquinolinecarboxamide. $\quad\left[{ }^{11} \mathrm{C}\right] \mathrm{Ro5}-4864$ was prepared using a captive solvent method [19], and $\left[{ }^{11} \mathrm{C}\right]$ PK 11195 was prepared and purified using the method of Camsonne and colleagues [20], with minor modifications. Radiochemical purities were greater than $99 \%$, and specific activities at injection ranged from 30 to $156 \mathrm{mCi} / \mu \mathrm{mol}$ for $\left[{ }^{11} \mathrm{C}\right] \mathrm{Ro} 05-4864$ and 20 to $193 \mathrm{mCi} / \mu \mathrm{mol}$ for $\left[{ }^{11} \mathrm{C}\right] \mathrm{PK}$ 11195. Injected doses were $15 \mathrm{mCi}$ of $\left.{ }^{11} \mathrm{C}\right] \mathrm{Ro}-4864$ and $24 \mathrm{mCi}$ of $\left[{ }^{11} \mathrm{C}\right] \mathrm{PK} 11195$, in most patients.

PET was performed using a PCT $4600 \mathrm{~A}$ tomograph, which has a resolution of $1.1 \times 1.1 \times 0.95 \mathrm{~cm}$. Five planes with center-to-center spacing of $1.15 \mathrm{~cm}$ are scanned simultaneously with this tomograph. A dynamic series of 7 or more PET frames of progressively increasing duration was recorded over 80 minutes. In 3 patients scanned with $\left[{ }^{11} \mathrm{C}\right]$ Ro $5-4864$ and 4 with $\left[{ }^{11} \mathrm{C}\right] P K 11195$, a minimum of 16 PET frames were recorded over 80 minutes, and sequential arterial blood samples were obtained at 5- to 10-second intervals during the first 2 minutes and less frequently thereafter for measurement of radioactivity. For the $\left[{ }^{11} \mathrm{C}\right] \mathrm{Ro5}-4864$ scans, hydrophilic metabolites were isolated from blood by $\mathrm{C}_{18}$ reverse-phase SepPak column chromatography (Waters Associates, Milford, MA). In patients who underwent arterial blood collection, dynamic scans of local blood flow were also performed at the same brain levels after intravenous injection of $\left[{ }^{15} \mathrm{O}^{2} \mathrm{H}_{2} \mathrm{O}[21]\right.$.

Regions of interest that were defined represented tumor, gray matter, and white matter. For tumor, we used an approach designed to define regions of interest encompassing the portions of tumor with relatively high activity on scans at 40 to 80 minutes after injection. First, the tumor was delineated in either one or two planes on the CT scan, and these regions were mapped to the PET scans using a planimetric approach. Second, within these regions we determined the average pixel value in the highest $5 \%$ of pixels, and all pixels with values greater than $75 \%$ of that value were included within the tumor region of interest. This approach generated contiguous regions of interest averaging $8.6 \pm 9.4$ $\mathrm{cm}^{2}$ in area for $\left.{ }^{[11} \mathrm{C}\right] \mathrm{Ro} 05-4864$ scans and $8.6 \pm 6.9 \mathrm{~cm}^{2}$ for $\left[{ }^{11} \mathrm{C}\right] \mathrm{PK} 11195$ scans. These regions encompassed 59 $\pm 23 \%$ of the total area of the CT-mapped region for $\left[{ }^{11} \mathrm{C}\right] \mathrm{R}$ o5-4864 scans and $66 \pm 23 \%$ for $\left[{ }^{11} \mathrm{C}\right] \mathrm{PK} 11195$ scans. Regions representing gray matter were defined on 0 to 5-minute scans as a 1.1-cm-thick band following the peak radioactivity in contralateral frontal, temporoparietal, and calcarine cortex and as a $1.1 \times 1.5-\mathrm{cm}$ ellipse over the peak radioactivity for thalamus. Regions representing white matter were defined in the centrum semiovale above the level of the lateral ventricle. Correlations of regional radioactivity or radioactivity ratios with specific activity were performed using the nonparametric Spearman rank test.

In the patients who underwent arterial blood sampling, the transfer constant $K_{1}$ for passage from blood to tissue was estimated by nonlinear least squares fitting of the values for blood and tissue radioactivity to a three-compartment model for receptor binding [22]. Because the fraction of ${ }^{11} \mathrm{C}$ activity associated with $\left[{ }^{11} \mathrm{C}\right] \mathrm{PK} 11195$ metabolites in blood and brain is unknown, we do not have confidence in the fitted $k_{2}$ and $k_{3}$ values, and these are not reported. In contrast, $K_{1}$ values depend primarily on data from the first few minutes and are not influenced substantially by metabolism. For $\left[{ }^{11} \mathrm{C}\right] \mathrm{PK} 11195$, we also estimated $K_{1}$ by fitting the data from the first 15 minutes to a two-compartment model. The absolute difference between the $K_{1}$ values derived from the three-compartment model and those derived from the twocompartment model averaged only $7 \%$ for tumor regions and $9 \%$ for brain regions.

\section{In Vitro Autoradiography}

Sections $(6 \mu \mathrm{m})$ from frozen specimens taken at biopsy were thaw-mounted onto gelatin-coated slides. The sections were prewashed three times for 5 minutes each in $5 \mathrm{mM}$ tris- $\mathrm{HCl}$ buffer, $\mathrm{pH} 7.4$, and then incubated for 60 minutes at $4^{\circ} \mathrm{C}$ in the same buffer containing either $1 \mathrm{nM}\left[{ }^{3} \mathrm{H}\right] \mathrm{PK} 11195$ or 2 $\left.\mathrm{nM} \mathrm{I}^{3} \mathrm{H}\right] \mathrm{Ro}$ 5-4864. Unlabeled ligand $(10 \mu \mathrm{M})$ was added for incubation of the blanks. The sections were postwashed three times for 5 minutes each in cold buffer, dried in a stream of cool air, placed in $\mathrm{x}$-ray cassettes with radioactive standards, and apposed to Ultrofilm ${ }^{3} \mathrm{H}$ (LKB, Bromma, Sweden) for 2 weeks at $4^{\circ} \mathrm{C}$. The resulting images were analyzed by computer-assisted densitometry [23]. Statistical analysis was performed using the two-tailed paired sample $t$ test on logarithmically transformed data.

\section{Results}

The images from the first several minutes after injection of $\left[{ }^{11} \mathrm{C}\right]$ Ro5-4864 (Fig 1) resembled the blood 


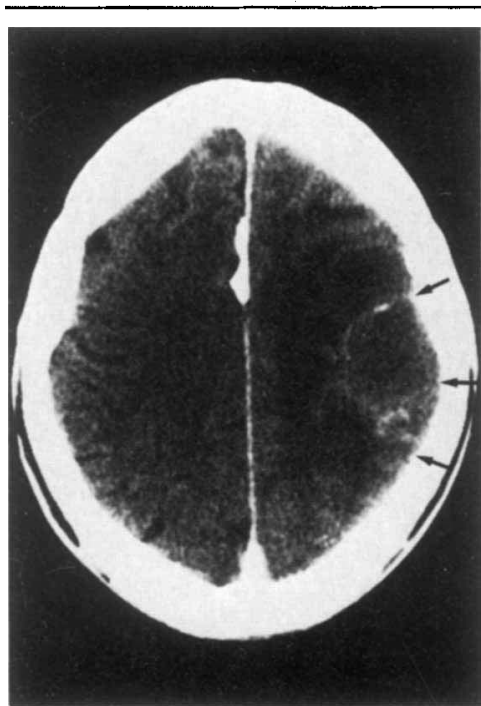

A

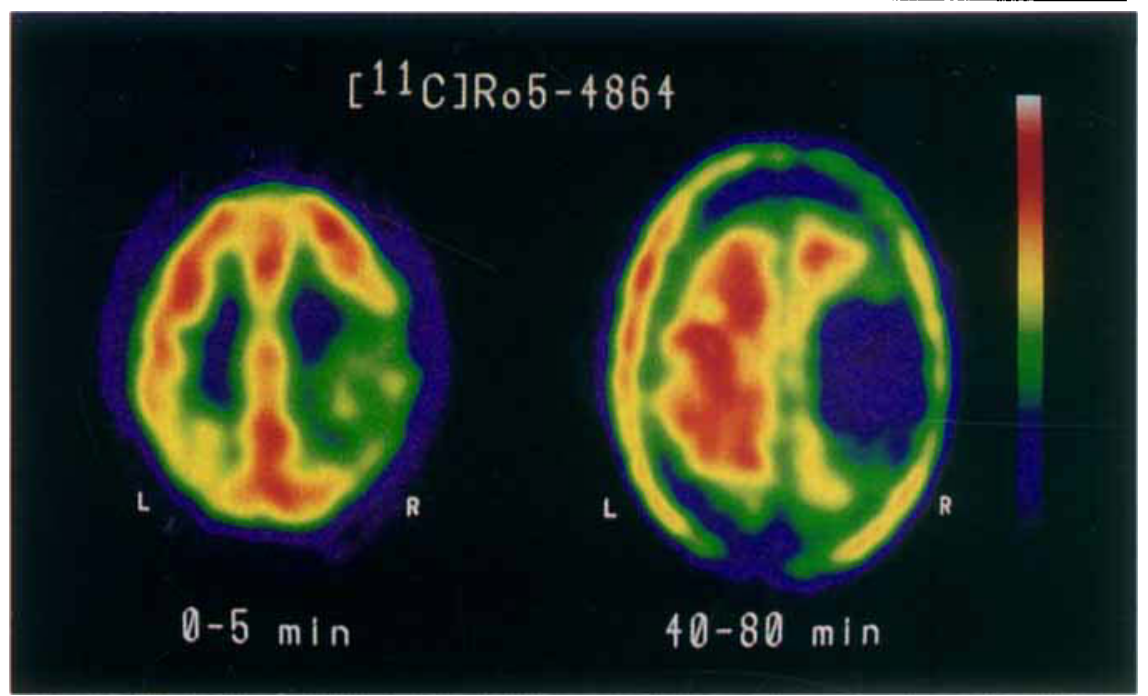

B

Fig 1. Patient with grade III mixed glioma of the right parietal region. (A) Computed tomographic scan after intravenous injection of contrast agent. The arrows indicate the tumor. (B) Positron emission tomographic (PET) scans performed $O$ to 5 minutes and 40 to 80 minutes after injection of $\left(^{11} \mathrm{CHR}\right.$ 05-4864. The absolute scaling of the PET scans is arbitrary. The color bar indicates the relative intensity represented by each color. Radioactivity at 40 to 80 minutes is bighest in scalp tissue.

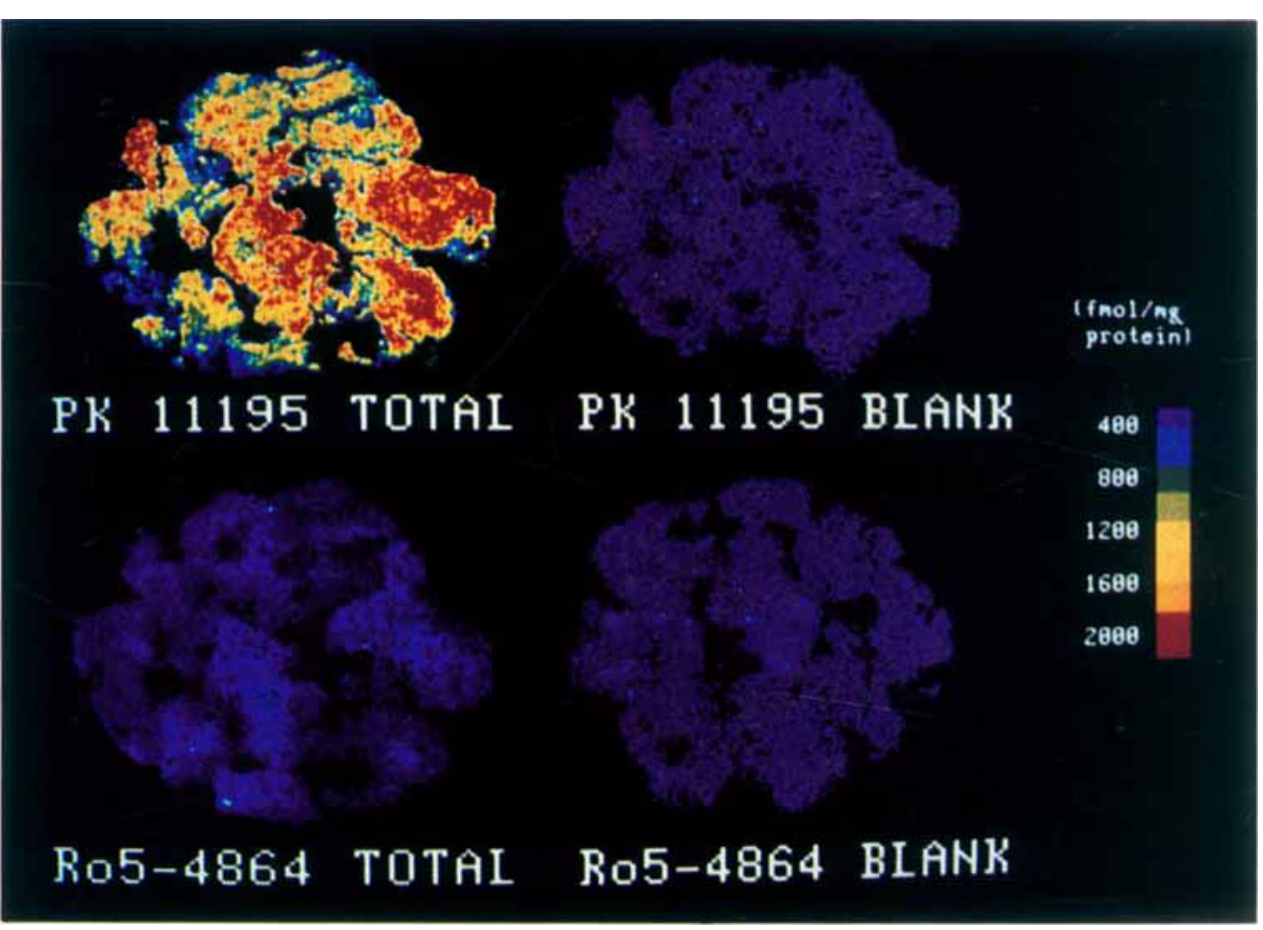

Fig 2. Autoradiographic comparison of $1 \mathrm{nM}\left({ }^{3} \mathrm{H}\right) P \mathrm{~K} 11195$ and $\left({ }^{3} H\right) R 05-4864$ binding in adjacent sections of a grade III astrocytoma biopsy specimen. The color bar indicates the relative radioactivity corresponding to each color. 


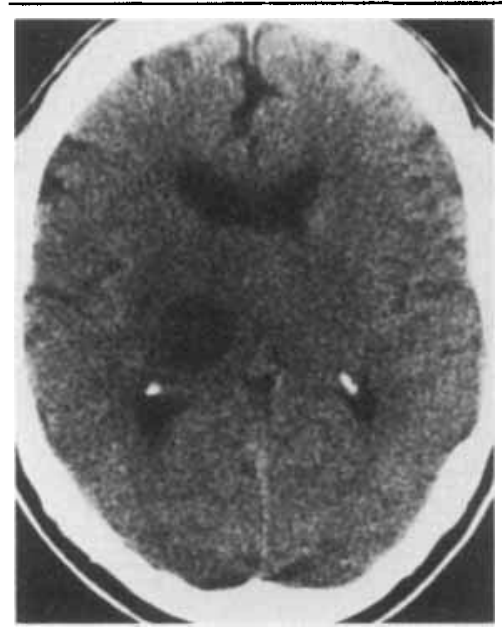

A

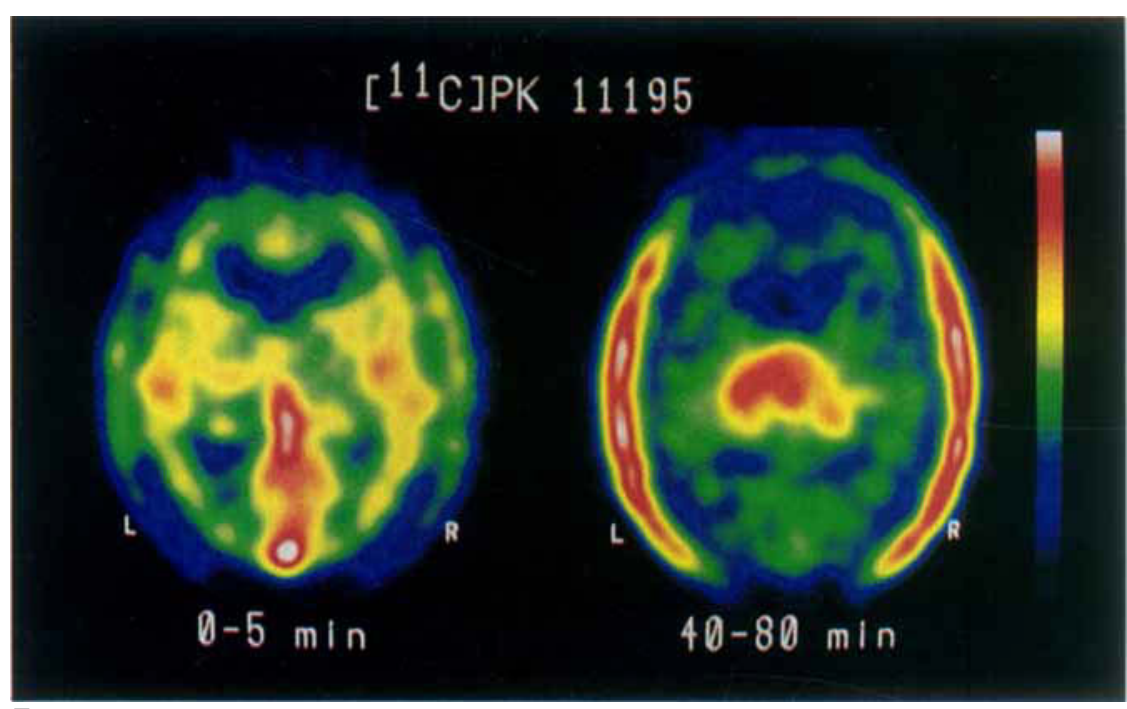

B
Fig 3. Patient with astrocytoma of indeterminate grade, as proved by examination of biopsy specimen. (A) Computed tomograpbic scan after infusion of contrast medium. The tumor in the left thalamus does not manifest contrast enbancement. A slight decrease in attenuation extends into the right thalamus. (B) Positron emission tomographic scans performed 0 to 5 and 40 to 80 minutes after injection of $\left(^{11} \mathrm{C}\right) P K 11195$. Radioactivity in the later images is bighest in tumor (1.88 times that in remote gray matter) and in scalp. Increased radioactivity extends into the right thalamus.

Table 1. Transfer Constant $\left(\mathrm{K}_{1}\right)$, Blood Flow, and Unidirectional Extraction $\left(\mathrm{K}_{1} /\right.$ blood flow) from $\left({ }^{11} \mathrm{C}\right)$ Ro5-4864 Positron Emission Tomograpbic Studies $(n=3)^{\mathrm{a}}$

\begin{tabular}{llll}
\hline & $\begin{array}{l}K_{1} \\
(\mathrm{ml} / \mathrm{gm} \cdot \mathrm{min})\end{array}$ & $\begin{array}{l}\text { Blood Flow } \\
(\mathrm{ml} / \mathrm{gm} \cdot \mathrm{min})\end{array}$ & $\begin{array}{l}\text { Extraction } \\
(\%)\end{array}$ \\
\hline Tumor & $0.168 \pm 0.119$ & $0.56 \pm 0.27$ & $29 \pm 11$ \\
Gray matter & $0.139 \pm 0.046$ & $0.53 \pm 0.21$ & $29 \pm 15$ \\
White matter & $0.094 \pm 0.047$ & $0.30 \pm 0.13$ & $34 \pm 20$ \\
\hline
\end{tabular}

${ }^{2}$ Values represent mean \pm SD.

flow images, with radioactivity (per unit volume) in the gray matter being higher than that in the tumor, which was higher than that in the white matter. Late images showed accumulation of radioactivity in white matter, with radioactivity in the white matter being higher than that in gray matter, which was higher than the radioactivity in the tumor. The ratio of radioactivity in tumor to that in remote gray matter at 60 to 80 minutes averaged $0.72 \pm 0.15$ (mean $\pm S D$ ). In no case did tumor achieve higher radioactivity than gray matter or white matter in late images. The results of kinetic analysis indicated that blood vessels in tumor and brain were permeable to $\left[{ }^{11} \mathrm{C}\right] \mathrm{Ro}-4864$ (Table 1). One or more hydrophilic metabolites accounted for $54 \pm$ $11 \%$ (mean \pm SD) of the radioactivity in blood at 80 minutes after injection.
The unexpected imaging results with $\left[{ }^{11} \mathrm{C}\right]$ Ros4864 prompted us to examine binding to the PBBS in vitro in 3 human grade III or IV astrocytoma taken at biopsy specimens [18]. The specimens displayed little binding of $\left[{ }^{3} \mathrm{C}\right] \mathrm{R} 05-4864$, and the majority of the binding was nonspecific (Table 2, Fig 2). In contrast, specific binding of $\left[{ }^{3} \mathrm{H}\right] \mathrm{PK} 11195$ was high and significantly exceeded binding of $\left[{ }^{3} \mathrm{H}\right] \mathrm{Ro} 05-4864$.

After obtaining these in vitro results, we imaged patients with gliomas using $\left[{ }^{11} \mathrm{C}\right] \mathrm{PK} 11195$ (Fig 3). In the early images radioactivity was approximately equal in the gray matter and tumor and higher in both of these regions than in the white matter. High radioactivity was also noted in large venous structures. In 8 of 10 patients, the late images showed a visually recognizable pattern of increased radioactivity in tumor. Radioactivity in the 60- to 80-minute images was highest in the tumor, which had more radioactivity than gray matter, which in turn had more than the white matter. The ratio of radioactivity in tumor to that in remote gray matter typically reached a plateau at approximately 40 minutes. At 60 to 80 minutes, the tumor/ gray matter ratio was $1.41 \pm 0.39$ (mean $\pm \mathrm{SD}$ ) (Table 3). The tumor/gray matter ratio averaged 1.75 \pm 0.18 in 5 patients studied at specific activities of 123 to $193 \mathrm{mCi} / \mu \mathrm{mol}$ and $1.08 \pm 0.17$ in 5 patients studied at specific activities of 20 to $52 \mathrm{mCi} / \mu \mathrm{mol}$. For comparison, the tumor/gray matter ratios measured using the entire CT-mapped regions were $1.29 \pm 0.41$ for the entire group, $1.61 \pm 0.29$ for the $S$ patients studied at higher specific activity, and $0.96 \pm 0.17$ for those studied at lower specific activity. The specific activity at injection correlated with the tumor/gray matter ratio $(p<0.02)$ and with the tumor/white matter ratio $(p<0.01)$. The specific activity also correlated with absolute tumor radioactivity at 60 to 80 
Table 2. Binding of Selective Ligands for the Peripheral-Type Benzodiazepine Binding Site In Vitro in 3 Specimens of Human Glioma Taken at Biopsy

\begin{tabular}{lcccc}
\hline & \multicolumn{4}{c}{ Binding (fmol/mg of protein) } \\
\cline { 2 - 5 } Ligand & Specimen 1 & Specimen 2 & Specimen 3 & Mean \\
\hline$\left.{ }^{3} \mathrm{H}\right]$ Ro5-4864 & 241 & 136 & 85 & 154 \\
Total binding & 95 & 22 & 10 & $42^{\mathrm{a}}$ \\
Specific binding & & 391 & 308 & 812 \\
{$\left[{ }^{3}\right.$ H]PK 11 195 } & 1,738 & 363 & 278 & $785^{\mathrm{a}}$ \\
Total binding & 1,715 & & & \\
Specific binding &
\end{tabular}

${ }^{a} p<0.003$, specific binding of $\left[{ }^{3} \mathrm{H}\right] \mathrm{PK} 11195$ differs from specific binding of $\left[{ }^{3} \mathrm{H}\right] \mathrm{Ro} 5-4864$.

Table 3. Ratios of Tumor to Gray Matter from Positron Emission Tomographic Scans 60 to 80 Minutes after $\left({ }^{11} \mathrm{C}\right) P K$ 11195 Injection

\begin{tabular}{lll}
\hline $\begin{array}{l}\text { Astrocytoma } \\
\text { Histology }\end{array}$ & $\begin{array}{l}\text { Specific Activity } \\
(\mathrm{mCi} / \mu \mathrm{mol})\end{array}$ & $\begin{array}{l}\text { Tumor/Gray Matter Ratio } \\
(60-80 \mathrm{~min})\end{array}$ \\
\hline Indeterminate & 193 & 1.88 \\
Grade II & 184 & 1.84 \\
Grade IV & 180 & 1.53 \\
Grade III & 150 & 1.57 \\
Grade II & 123 & 1.91 \\
Grade IV & 52 & 1.17 \\
Grade III & 49 & 0.87 \\
Grade IV & 36 & 1.28 \\
Grade III & 36 & 0.96 \\
Grade II & 20 & 1.13 \\
\hline
\end{tabular}

Table 4. Transfer Constant $\left(\mathrm{K}_{\mathrm{I}}\right)$, Blood Flow, and Unidirectional Extraction from $\left({ }^{12} \mathrm{C}\right) P K 11195$ Positron Emission Tomograpbic Studies $(n=4)^{\mathrm{a}}$

\begin{tabular}{llll}
\hline & $\begin{array}{l}K_{1} \\
(\mathrm{ml} / \mathrm{gm} \cdot \mathrm{min})\end{array}$ & $\begin{array}{l}\text { Blood Flow } \\
(\mathrm{ml} / \mathrm{gm} \cdot \mathrm{min})\end{array}$ & $\begin{array}{l}\text { Extraction } \\
(\%)\end{array}$ \\
\hline Tumor & $0.027 \pm 0.014$ & $0.40 \pm 0.17$ & $7.5 \pm 4.4$ \\
Gray matter & $0.028 \pm 0.011$ & $0.55 \pm 0.06$ & $4.9 \pm 1.4$ \\
White matter & $0.013 \pm 0.007$ & $0.28 \pm 0.08$ & $4.4 \pm 1.7$ \\
\hline
\end{tabular}

${ }^{a}$ Values represent mean $\pm S D$.

minutes normalized to injected dose and body weight $(p<0.05)$. The tumor/gray matter ratio, tumor/white matter ratio, and tumor radioactivity did not correlate with tumor grade. Kinetic analysis demonstrated that $K_{1}$ was similar in tumor and in gray matter structures (Table 4). In the 7 tumors delineated on CT by contrast enhancement, high $\left[{ }^{11} \mathrm{C}\right] \mathrm{PK} 11195$ radioactivity was seen in a configuration similar to the enhancement, but in 2 of these tumors, high radioactivity extended into areas without contrast enhancement. Only 1 tumor without contrast enhancement was studied at high specific activity, and that tumor had a tumor/gray matter ratio of 1.88 (see Fig 3).

\section{Discussion}

These results demonstrate that the density of PBBS is higher in human gliomas than in normal brain and that radiolabeled PBBS ligands can be used to image human gliomas. The pharmacological properties of the PBBS in human gliomas studied in vitro with autoradiography and in vivo with PET are similar to those of human glioma cell lines studied in culture [16] but different from those of human gliomas implanted in athymic rats, where both PK 11195 and Ro5-4864 bind avidly [15]. The milieu of the rat brain may cause the properties of the PBBS in implanted gliomas to differ from those expressed in gliomas in the human brain or in human gliomas in cell culture.

Langer and Arbilla [9] proposed a new nomenclature in which the subtypes of central benzodiazepine receptors are renamed the $\omega_{1}$ and $\omega_{2}$ sites and the PBBS is renamed the $\omega_{3}$ site. Among the reasons for renaming the PBBS are the arguments that drugs other than benzodiazepines, including the isoquinoline PK 11195 , are ligands for the PBBS and that the PBBS is expressed in the CNS as well as at peripheral sites. On the other hand, one possible explanation for our finding of differences between the pharmacological properties of the PBBS studied in various systems is that the PBBS may comprise two or more different sites. We do not disagree with the need for a new nomenclature, but we are reluctant to assign a single new name to the PBBS until it is more certain that it represents a single binding site.

The isoquinoline derivative PK 11195 appears to be superior to the benzodiazepine Ro5-4864 for imaging the PBBS in human gliomas. While this study was in progress, Bergstrom and colleagues reported that $\left[{ }^{11} \mathrm{C}\right] \mathrm{R} 05-4864$ did not achieve higher radioactivity in human gliomas than in brain, in agreement with our findings [24]. Our findings on surgically removed specimens of glioma also agree with the results on specimens of glioma obtained at autopsy [16]. With our $\left[{ }^{11} \mathrm{C}\right] \mathrm{PK} 11195$ imaging studies, the strong correlations observed between specific activity and tumor radioactivity suggest that most of the binding sites are 
occupied at the lower specific activities, and this finding supports the view that the increased radioactivity in tumor is due to high-affinity binding to the PBBS. In the 5 patients studied at lower specific activity, the peak amount of PK 11195 in tumor $(3.3-15.0 \mathrm{nmol} /$ $\left.1,000 \mathrm{~cm}^{3}\right)$ is similar to the dissociation constant $\left(K_{\mathrm{d}}\right)$ of the PBBS, which has been estimated at 0.8 to 15.8 $\mathrm{nM}$ in human brain tissue and in gliomas $[14,16,25]$; thus, the amount of unlabeled PK 11195 present in tumor in these cases may have been enough to occupy most of the PBBS, resulting in decreased binding of $\left[{ }^{11} \mathrm{C}\right] \mathrm{PK} 11195$. Scans at higher specific activities may yield greater contrast between tumor and brain than that reported here. Our findings of high $\left[{ }^{11} \mathrm{C}\right] \mathrm{PK}$ 11195 radioactivity in a non-contrast-enhancing glioma and of nearly equal $K_{1}$ values in tumor and remote gray matter indicate that disruption of the blood-brain barrier is not the basis for the positive imaging results.

The density of PBBS has been shown to be increased in lesions characterized by reactive gliosis and phagocytosis, including excitotoxic lesions and infarcts in animals $[12,13,26]$ and infarcts and multiple sclerosis plaques in humans [17]. The binding observed in our in vitro study and the accumulation in our PET study may be due to the high density of astrocyres in gliomas or to increased expression of the binding site in gliomas. It is unlikely that reactive gliosis adjacent to the tumors and phagocytosis in the tumors are responsible because ligand binding to PBBS is high in cultured glioma cells and in tumor regions densely populated with viable tumor cells $[15,16]$ and because ligand binding to PBBS is absent or low in pheochromocytoma and neuroblastoma implanted in rat brain [15]. If scans with PBBS ligands such as $\left[{ }^{11} \mathrm{C}\right] \mathrm{PK} 11195 \mathrm{dem}-$ onstrate increased radioactivity in non-neoplastic lesions with reactive gliosis, then such scans could prove diagnostically useful in such conditions. Scans with $\left[{ }^{11} \mathrm{C}\right] \mathrm{PK} 11195$ or other PBBS ligands may still be able to differentiate gliomas from reactive gliosis because the density of PBBS appears to be significantly greater in gliomas than in reactive gliosis [17]. Furthermore, it is not known whether the pharmacological properties of the PBBS on reactive glia are similar to those we observed in gliomas, but if they are different, imaging with two different radiolabeled PBBS ligands might provide an approach for differentiating gliomas from reactive gliosis.

Scans with $\left[{ }^{11} \mathrm{C}\right] \mathrm{PK} 11195$ or another radiolabeled PBBS ligand may prove useful in several ways in the diagnosis and management of gliomas. Potentially, they could prove valuable for distinguishing gliomas from other types of tumors and for predicting the prognosis of the patient. By showing the full extent of the tumor, such scans could be useful for guiding surgical resection or biopsy and for planning radiotherapy. Such scans might be used to distinguish viable from necrotic tumor and to assess the response of the tumor to treatment. Scans demonstrating PBBS may be possible using radioiodinated derivatives of PK 11195 and single photon tomography $[27,28]$, and such scans could be performed at centers lacking facilities for PET.

This work was supported by Teacher Investigator Development Award 5K07 NS00900 awarded to Dr Junck and by Grants NS 15655 and 5 T32 CA09015 from the National Institutes of Health.

We thank the staff of the Division of Nuclear Medicine for their assistance in carrying out these investigations. Unlabeled desmethyl PK 11195 was kindly supplied by Rhone-Poulenc.

\section{References}

1. Clasen RA, Huckman MS, Von Roenn DA, et al. A correlative study of compured tomography and histology in human and experimental vasogenic cerebral edema. J Comput Assist Tomogr 1981;5:313-327

2. Lilja A, Bergstrom K, Spännare B, Olsson Y. Reliability of computed tomography in assessing histopathological features of malignant supratentorial gliomas. J Comput Assist Tomogr 1981;5:625-636

3. Burger PC, Heinz ER, Shibata T, Kleihues P. Topographic anatomy and $\mathrm{CT}$ correlations in the untreated glioblastoma multiforme. J Neurosurg 1988;68:698-704

4. Kelly PJ, Daumas-Duport C, Scheithauer BW, et al. Stereotactic histologic correlations of computed tomography- and magnetic resonance imaging-defined abnormalities in patients with glial neoplasms. Mayo Clin Proc 1987;62:450-459

5. Felix R, Schorner W, Laniado M, et al. Brain tumors: MR imaging with gadolinium-DTPA. Radiology 1985;156:681-688

6. Zimmerman RA, Bilaniuk LT, Grossman RI, et al. Cerebral NMR: diagnostic evaluation of brain tumors by partial saturation technique with resistive NMR. Neuroradiology 1985; $27: 9-15$

7. Earnest F, Kelly PJ, Scheithauer BW, et al. Cerebral astrocytomas: histopathologic correlation of MR and CT contrast enhancement with stereotactic biopsy. Radiology 1988;166:823827

8. Dooms GC, Hecht S, Brant-Zawadzki M, et al. Brain radiation lesions: MR imaging. Radiology 1986;158:149-155

9. Langer SZ, Arbilla S. Limitations of the benzodiazepine receptor nomenclature: a proposal for a pharmacological classification as omega receptor subtypes. Fundam Clin Pharmacol 1988;2: $159-170$

10. Anholt RRH, De Souza EB, Oster-Granite ML, Snyder SH. Peripheral-type benzodiazepine receptors: autoradiographic localization in whole-body sections of neonatal rats. J Pharmacol Exp Ther 1985;233:517-526

11. McCarthy KD, Harden TK. Identification of two benzodiazepine binding sites on cells cultured from rat cerebral cortex. $\mathrm{J}$ Pharmacol Exp Ther 1981;216:183-191

12. Gallager DN, Mallorga $P$, Oertel W, et al. $\left\{^{3} \mathrm{H}\right\}$ Diazepam binding in mammalian central nervous system: a pharmacological characterization. J Neurosci 1981;1:218-225

13. Schoemaker H, Morelli M, Deshmukh P, Yamamura HI. $\left[{ }^{3} \mathrm{H}\right] \mathrm{R} 05-4864$ benzodiazepine binding in the kainate lesioned striatum and Huntington's diseased basal ganglia. Brain Res 1982;248:396-401

14. Bender AS, Hertz L. Flunitrazepam binding to intact and homogenized astrocytes and neurons in primary culture. I Neurochem 1984;43:1319-1327 
15. Starosta-Rubinstein S, Ciliax BJ, Penney JB, et al. Imaging of a glioma using peripheral benzodiazepine receptor ligands. Proc Natl Acad Sci USA 1987;84:891-895

16. Olson JMM, Junck L, Young AB, et al. Isoquinoline and peripheral-type benzodiazepine binding in gliomas: implications for diagnostic imaging. Cancer Res 1988;48:5837-5841

17. Benavides J, Cornu P, Dennis T, et al. Imaging of human brain lesions with an $\omega_{3}$ site ligand. Ann Neurol 1988;24:708-712

18. Zülch KJ. Histological typing of tumours of the central nervous system. International Classification of Tumours, No. 21. Geneva: World Health Organization, 1979:43-51

19. Watkins GL, Jewett DM, Mulholland GK, et al. A captive solvent method for rapid $\mathrm{N}-\left[{ }^{11} \mathrm{C}\right]$ methylation of secondary amides: application to the benzodiazepine, 4'-chlorodiazepam (Ros4864). Int J Rad Appl Instrum [A] 1988;39:441-444

20. Camsonne R, Crouzel C, Comar D, et al. Synthesis of N$\left({ }^{1} \mathrm{C}\right)$ methyl, $\mathrm{N}$-(methyl-1 propyl), (chloro-2 phenyl)-1 isoquinoline carboxamide-3 (PK 11195): a new ligand for peripheral benzodiazepine receptors. J Labelled Comp Radiopharm 1984;21:985-991

21. Alpert NM, Eriksson L, Chang JY, et al. Strategy for the measurement of regional cerebral blood flow using short-lived tracers and emission tomography. J Cereb Blood Flow Metab 1984;4:28-34

22. Frey KA, Hichwa RD, Ehrenkaufer RLE, Agranoff BW. Quantitative in vivo receptor binding III: tracer kinetic modeling of muscarinic cholinergic receptor binding. Proc Natl Acad Sci USA 1985;82:6711-6715

23. Pan HS, Frey KA, Penney JB, Young AB. Changes in $\left[{ }^{3} \mathrm{H}\right]$ muscimol binding in substantia nigra, entopeduncular nucleus, globus pallidus, and thalamus after striatal lesions as demonstrated by quantitative receptor autoradiography. J Neurosci 1984;3:1189-1193

24. Bergstrom M, Mosskin M, Ericson $K$, et al. Peripheral benzodiazepine binding sites in human gliomas evaluated with positron emission tomography. Acta Radiol [Suppl] (Stockh) 1986; 369:409-411

25. Doble A, Malgouris C, Daniel M, et al. Labelling of peripheraltype benzodiazepine binding sites in human brain with $\left[{ }^{3} \mathrm{H}\right] \mathrm{PK}$ 11195: anatomical and subcellular distribution. Brain Res Bull 1987; 18:49-61

26. DuBois $A$, Benavidès J, Peny $B$, et al. Imaging of primary and remote ischaemic and excitotoxic brain lesions. An autoradiographic study of peripheral type benzodiazepine binding sites in the rat and cat. Brain Res 1988;445:77-90

27. Gildersleeve DL, Lin TY, Wieland DM, et al. Synthesis of a high specific activity $\left.{ }^{125} \mathrm{I}\right]$-labeled analog of PK 11195 , potential agent for SPECT imaging of the peripheral benzodiazepine binding site. Nucl Med Biol 1989;16:423-429

28. Ciliax BJ, Starosta-Rubinstein S, Wieland DM, et al. In vivo imaging of rat $\mathrm{C} 6$ gliomas by [ $\left.{ }^{125} \mathrm{I}\right]$-iodinated benzodiazepines and isoquinolines. Soc Neurosci Abstr 1987;13:952 